\title{
Mouse models of Alzheimer's disease cause rarefaction of pial collaterals and increased severity of ischemic stroke
}

\author{
Hua Zhang ${ }^{1,2} \cdot$ Bo Jin ${ }^{3} \cdot$ James E. Faber ${ }^{1,2}$ \\ Received: 11 August 2018 / Accepted: 20 November 2018 / Published online: 5 December 2018 \\ (c) The Author(s) 2018
}

\begin{abstract}
Vascular dysfunction contributes to the progression and severity of Alzheimer's disease (AD). Patients with AD also sustain larger infarctions after ischemic stroke; however, the responsible mechanisms are unknown. Pial collaterals are the primary source of protection in stroke. Unfortunately, natural aging and other vascular risk factors cause a decline in collateral number and diameter (rarefaction) and an increase in stroke severity. Herein, we tested the hypothesis that AD accelerates age-induced collateral rarefaction and examined potential underlying mechanisms. Triple and double transgenic mouse models of AD both sustained collateral rarefaction by 8 months of age, well before the onset of rarefaction caused by aging alone (16 months of age). Rarefaction, which did not progress further at 18 months of age, was accompanied by a twofold increase in infarct volume after MCA occlusion. AD did not induce rarefaction of similarly sized pial arterioles or penetrating arterioles. Rarefaction was minimal and occurred only at 18 months of age in a parenchymal vascular amyloid-beta model of AD. Rarefaction was not associated with amyloid-beta deposition on collaterals or pial arteries, nor was plaque burden or $\mathrm{CD} 11 \mathrm{~b}^{+}$cell density greater in brain underlying the collateral zones versus elsewhere. However, rarefaction was accompanied by increased markers of oxidative stress, inflammation, and aging of collateral endothelial and mural cells. Moreover, rarefaction was lessened by deletion of $\mathrm{CX}_{3} \mathrm{CR} 1$ and prevented by overexpression of eNOS. These findings demonstrate that mouse models of $\mathrm{AD}$ promote rarefaction of pial collaterals and implicate inflammation-induced accelerated aging of collateral wall cells. Strategies that reduce vascular inflammation and/or increase nitric oxide may preserve collateral function.
\end{abstract}

Keywords Collateral circulation $\cdot$ Alzheimer's disease $\cdot$ Cerebral amyloid angiopathy $\cdot$ Stroke

$\begin{array}{ll}\text { Abbreviations } \\ \text { A } \beta & \begin{array}{l}\text { Amyloid precursor protein- } \beta \text { peptides } \\ \text { (amyloid- } \beta \text { ) }\end{array} \\ \text { ACA } & \text { Anterior cerebral artery } \\ \text { AD } & \text { Alzheimer's disease } \\ \text { APP } & \text { Amyloid precursor protein } \\ \text { B6 } & \text { C57BL/6J inbred mouse strain }\end{array}$

Electronic supplementary material The online version of this article (https://doi.org/10.1007/s10456-018-9655-0) contains supplementary material, which is available to authorized users.

James E. Faber

jefaber@med.unc.edu

1 Department of Cell Biology and Physiology, University of North Carolina at Chapel Hill, 6309 MBRB, Chapel Hill, NC 27599-7545, USA

2 McAllister Heart Institute, University of North Carolina at Chapel Hill, Chapel Hill, USA

3 Zhejiang Chinese Medical University, Hangzhou, China
CAA Cerebral amyloid angiopathy

COL Collateral

$\mathrm{CX}_{3} \mathrm{CL} 1$ The ligand, also known as fractalkine, that binds $\mathrm{CX}_{3} \mathrm{CR} 1$

DMA Distal-most arteriole in a cerebral artery tree

EC Endothelial cell

HO-1 Heme oxygenase-1

hye Human-year equivalents (of age)

MCA Middle cerebral artery

eNOS Endothelial nitric oxide synthase

NO Nitric oxide

PA Penetrating arteriole (perforator)

PCA Posterior cerebral artery

pMCAO Permanent distal (post-lenticulostriate)

M1-MCA occlusion

SMC Smooth muscle cell

SOD2 Superoxide dismutase-2

WT Wildtype control littermates

1xTg-AD Single transgenic AD mouse strain, APPSwDI 
2xTg-AD Double transgenic AD mouse strain, APP695, PSEN-1

3xTg-AD Triple transgenic AD mouse strain, APPSw, PSEN-1, MAPT (Tau)

8-OHdG 8-hydroxy-2'-deoxyguanosine

\section{Introduction}

Alzheimer's disease (AD) affects more than 45 million people and is increasing with aging of the world's population [1]. The familial form is caused by mutations of amyloid precursor protein (APP) and $\gamma$-secretases, presenilin- 1 and -2, while alleles of APOE, TREM2, and several other genes, along with risk factors such as aging, diabetes, obesity, and hypertension, increase the risk of developing the more common sporadic late-onset form of the disease [2-5]. According to the "amyloid hypothesis", genetic and environmental factors result in altered processing of APP, accumulation of intracellular amyloid-beta peptides $(\mathrm{A} \beta)$ and the microtubule protein tau, imbalance between production, degradation, and clearance of $A \beta$ leading to accumulation of extracellular $\mathrm{A} \beta$, activation of microglia and astrocytes, and a cascade of events resulting in inflammation, synapse dysfunction, neuronal loss, and cognitive decline [2-5].

There is also substantial evidence that vascular abnormalities and the above neurodegenerative processes interact synergistically early-on to increase the risk and progression of $\mathrm{AD}$ [6-10]. Patients and animal models of AD undergo accumulation of $A \beta$ on blood vessels (cerebral amyloid angiopathy, CAA), recruitment of peripheral immune cells to the perivascular niche, disturbances in smooth muscle cell (SMC) reactivity and regulation of blood flow, and altered blood-brain barrier integrity. As well, increased risk of acute ischemic stroke, larger lesions, and worse outcomes have been reported in clinical and experimental studies of $\mathrm{AD}$. Presence of $A P O E-\varepsilon 4$ allele and CAA on autopsy increased the odds of cortical infarction threefold [11]. Other studies have also found, although not universally [12, 13], that $\mathrm{AD}$ increases the risk of ischemic stroke [14]. In mouse models of $\mathrm{AD}$, penumbral blood flow was lower and infarct volume larger following permanent MCA occlusion (pMCAO) [15-19] and photothrombotic occlusion [20]. The mechanisms responsible for these findings in stroke have not been investigated.

Pial collaterals are the primary source of protection in acute ischemic stroke [21-24]. Thus, AD-induced insufficiency of the pial collateral circulation could contribute significantly to the above findings. Conductance of the collateral network is mainly determined by the number and average diameter (i.e., extent) of pial collaterals interconnecting the affected territory to adjacent arterial trees [23, 24]. Unfortunately, collateral extent varies widely among individuals. In mice, pial collaterals form late during gestation and undergo perinatal maturation that determines their extent in the adult [25-28]. This collaterogenesis process varies widely due to differences in genetic background [23, 24, 26]. Environmental factors also affect collateral extent. Aging, hypertension, diabetes, endothelial dysfunction, and other vascular risk factors cause a decline or pruning away of collaterals and a smaller lumen diameter in those that remain (collateral rarefaction) [29-32]. Indirect measures of collaterals assessed during the hyperacute stage of stroke indicate that collateral conductance also varies widely in humans and is adversely affected by vascular risk factors [21, 22, 33-35]. The cause of this risk factor-induced rarefaction of collaterals, which does not occur in other pial vessels [29, 31], has been suggested to extend from a unique sensitivity of collaterals, created by the low and disturbed shear stress and high wall stress normally present in them, to diseases and conditions that increase oxidative stress and inflammation [29-32]. Of note, traditional vascular risk factors also increase the risk of, or are strongly associated with, $\mathrm{AD}$ and vascular cognitive impairment [3, 7, 36-39].

The purpose of this study was to determine if collateral rarefaction and more severe acute ischemic stroke occur in mice with $\mathrm{AD}$ and explore possible mechanisms. We studied single (APPSwDI), double (APP695, PSEN-1), and triple (APPSw, PSEN-1, MAPT (Tau)) transgenic mouse models of $\mathrm{AD}$ at 1,8 , and 18 months of age.

\section{Methods}

See the Online Supplement for details. Triple transgenic AD mice (3xTg-AD) were C57BL/6J (B6).129-PSen $1^{\text {tm } 1 M p m}$ Tg (APPSwe, tauP301L)1Lfa/Mmjax (homozygous) [40]; wildtype (WT) controls were B6; 129S-F1/2J. 2xTg-AD mice were B6.Cg-Tg(APP695)3Dbo $\mathrm{Tg}$ (PSEN1dE9) S9Dbo/Mmjax] (hemizygous) [41]; controls were B6 WT littermates. 1xTg-AD mice were B6.Tg(Thy1-APPSwDutIowa) BWevn/Mmjax] (homozygous) [42]; controls were B6/J.B6/NJ-F1. B6.CX ${ }_{3} \mathrm{CR}_{1}{ }^{-1-}$ were B6.129P(Cg)-Ptprc ${ }^{\mathrm{a}}$

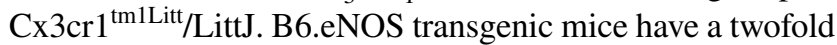
increase in NO production [32]. Approximately, equal numbers of males and females were studied in each experiment. The scope of this study did not include the investigation of the effects of sexual dimorphism in AD-induced collateral rarefaction. In a previous study, the observed effects of sex were negligible for native pial collateral number, diameter, and amount of rarefaction seen with aging in 3.5-, 8-, and 22-month-old B6 mice or 8 versus 18-month-old B6; 129SvEv mice [43]. Angiography was performed after perfusion-fixation at maximal dilation and filling of the precapillary vessels with viscosity-adjusted Microfil ${ }^{\circledR}$ [32]. All pial collaterals between the ACA and MCA trees of both 
hemispheres were identified and their anatomic (maximally dilated) lumen diameters were measured at midpoint and averaged for each animal. Collateral length, tortuosity, calculated relative resistance of the MCA-to-ACA collateral network, territories of the ACA, MCA, and PCA trees, and other morphometrics were also measured [23, 32]. Number and average diameter of the penetrating arterioles (PAs) diverging from the collaterals and branches of the ACA tree overlying the dorsal cortex were measured after optical clearing. Permanent MCA occlusion (pMCAO) was by occlusion of the M1-MCA just distal to the lenticulostriate branches [32]. Infarct volume $24 \mathrm{~h}$ later was by $2,3,5$-triphenyltetrazolium chloride, and immunofluorescent histology was by standard techniques [32]. The STAIR criteria adhered to included blinding to groups before and during analysis and no exclusion of data points.

\section{Results}

\section{Overexpression of mutant APP and presenilin-1 causes rarefaction of pial collaterals}

Collateral number and diameter were reduced by similar amounts in 8-month-old 3xTg-and 2 xTg-AD cohorts $(\sim 28$ human-year equivalents, hye [44]), compared to cohorts of controls comparable in age (Fig. 1). No additional decrease occurred at 18 months of age ( 56 hye). Absence of effect at 1 month indicates that the presence of fewer and smaller collaterals is not due to decreased collaterogenesis, which occurs in the perinatal period and determines collateral number and diameter in the adult [25-28]. The latter could possibly have occurred secondary to parenchymal $A \beta$ that has been detected in 1-month-old transgenic AD mice [45], or from non-specific effects of transgene insertion or private mutations/genetic drift in the AD strains. Rarefaction in the 8-month-old AD mice occurred much earlier than that caused by aging alone. The latter, which becomes evident at 16 and 24 months of age as a decrease in diameter and number, respectively, in B6 mice [29], was confirmed for diameter in $3 \times \mathrm{Tg}$ and $2 \mathrm{x}-\mathrm{Tg}$ WT mice at 18 months of age (Fig. 1). Although difficult to detect, occasional collaterals were observed, presumably late in the process of being pruned away, as a narrowing of the lumen of the centermost segment of a collateral to that approximating nearby capillaries (Supplemental Fig. I). 1xTg mice sustained no rarefaction at 8 months of age, and only a small decrease in collateral number was evident at 18 months of age (Fig. 1). This difference may reflect that, unlike in the $2 \times \mathrm{Tg}$ and $3 \mathrm{xTg}$ strains, vascular pathology in the $1 \times \mathrm{xTg}$ model manifests as
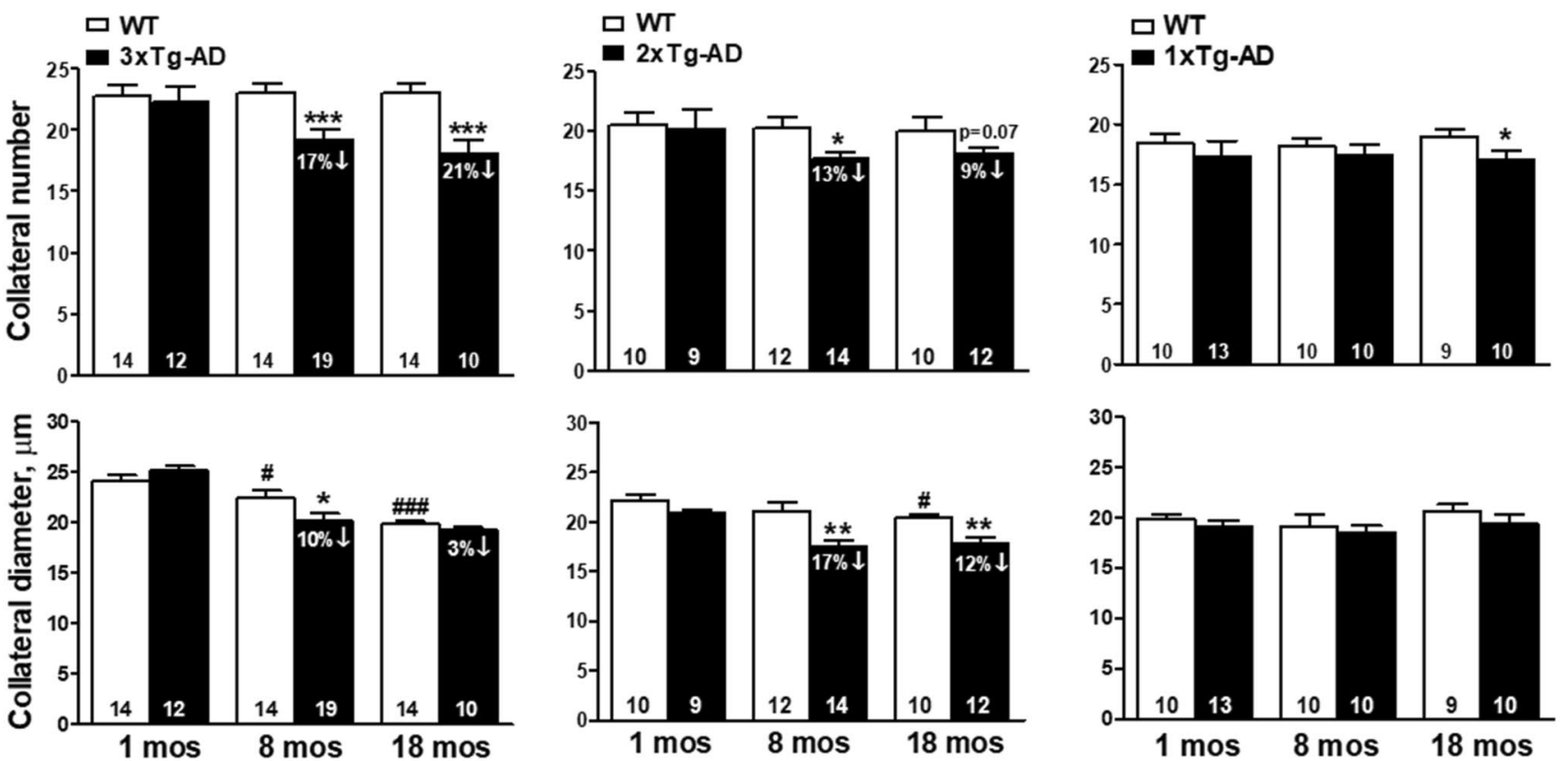

Fig. 1 Overexpression of mutant APP and presenilin-1 causes rarefaction of pial collaterals. Rarefaction in $3 \times \mathrm{Tg}-\mathrm{AD}$ and $2 \mathrm{xTg}-\mathrm{AD}$ mice, i.e., decline in collateral number and lumen diameter, occurred at an earlier age (mos, months) than rarefaction caused by aging alone. The latter was observed for diameter at 16 months of age and number at 24 months of age, respectively [36], a finding confirmed in 18-month-old 3xTg and 2x-Tg wildtype (WT) controls. 1xTg-AD mice evidenced a small loss in number at 18 months of age. In this and subsequent figures and tables, unless indicated otherwise: the total number and average lumen diameter of all MCA-ACA collaterals of both hemispheres are shown, values are mean \pm SEM, and numbers of animals are given in the bases of the bars. $* * * * * * * p<0.05$, $0.01,0.001$ versus age-matched WT. ${ }^{\#, \# \# p} p<0.05,0.0011$-month-old WT 
deposition of $\mathrm{A} \beta$ on intracerebral capillaries and arterioles with little deposition on pial vessels [42, 46, 47].

We quantified additional parameters in a second group of 8-month-old 3xTg and WT mice (Fig. 2). Collateral length, tortuosity, and calculated relative resistance of the collateral network interconnecting the MCA and ACA trees were increased in the AD mice by $37 \%, 34 \%$, and 2.9 -fold, respectively (Fig. 2a-d). Infarct volume $24 \mathrm{~h}$ after pMCAO
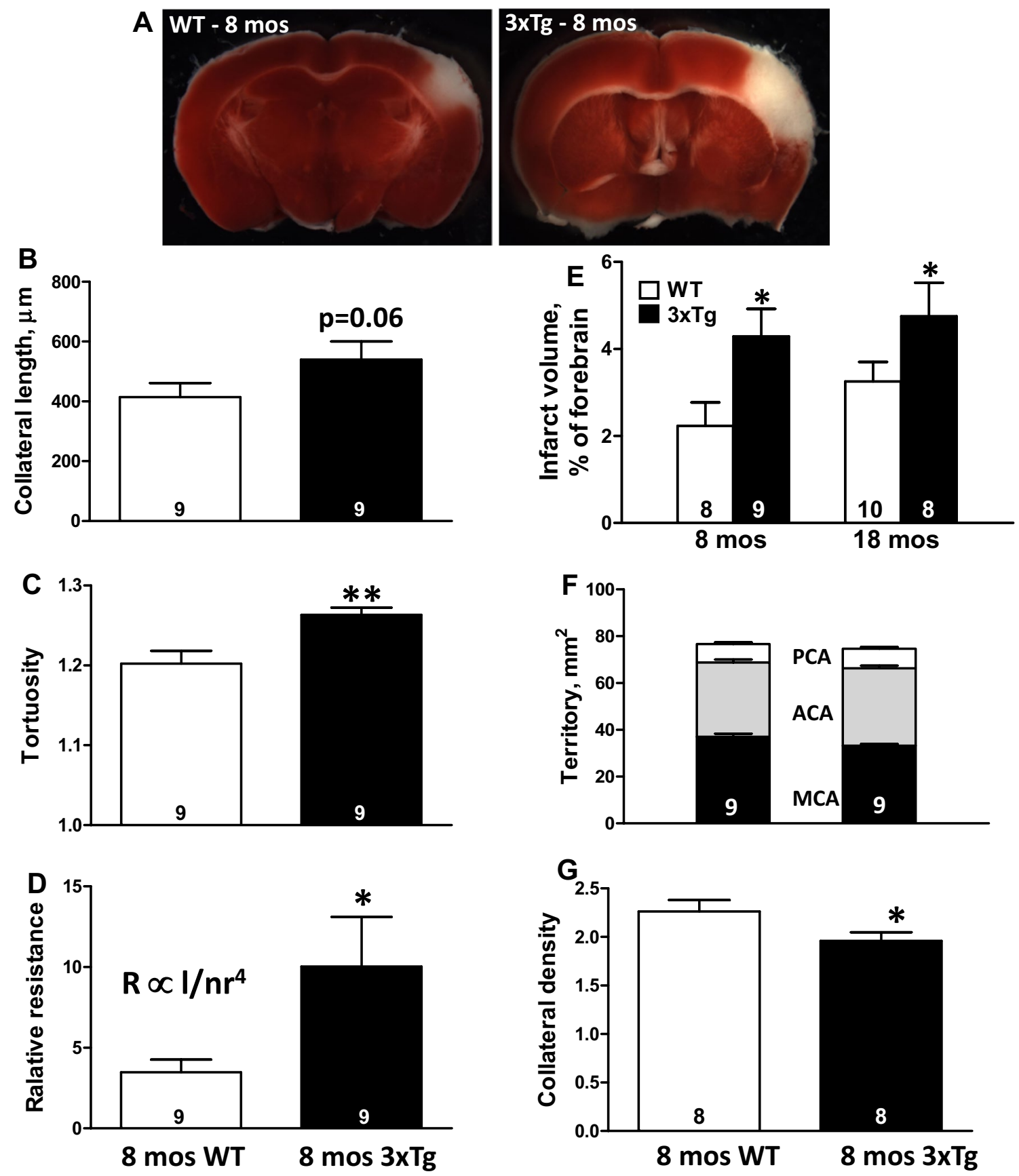

Fig. 2 AD-induced collateral rarefaction is accompanied by increased collateral tortuosity, resistance of the collateral network, and infarct volume (a-e), and is specific for collaterals. a Representative images of infarct volume (unstained/white). d Calculated relative resistance of the collateral network [average collateral length $\div$ (collateral number $\times$ average collateral radius [4])]. Increased infarct volume was also seen in 18-month-old 3xTg mice. The latter was in association with modestly reduced brain and body weight and area of the col-

lateral zone between the MCA-ACA trees (Supplemental Fig. II). f Territories of the cerebral artery trees. Collateral density (number per $\mathrm{mm}^{2}$ of collateral zone) remained reduced when normalized to collateral zone area (g). No loss of number or diameter occurred for distal-most arterioles of the MCA tree, which are nearby and of similar diameter as collaterals (Supplemental Fig. II), or for penetrating arterioles branching from the extant collaterals (Supplemental Fig. III). $* * * * p<0.05,0.01$ versus WT 
was increased 91\% (Fig. 2e), even though MCA tree territory tended to be slightly smaller (Fig. 2f). Infarct volume increased less (46\%) in 18-month-old 3xTg mice, reflecting the larger lesion evident in the age-matched WT controls (Fig. 2e). Body weight, brain weight, and area of the collateral zone between the MCA and ACA trees were modestly lower (Supplemental Fig. II). The latter is consistent with the smaller brain weight, which also occurs in human familial and sporadic AD [48]. Collateral number, when normalized to area of the collateral zone, remained reduced (Fig. 2g), indicating that collateral rarefaction was not secondary to the modest brain atrophy. No decrease in number and diameter occurred for distal-most arterioles (DMAs) of the pial artery trees, which have diameters similar to collaterals, or for PAs branching from the pial arteries/arterioles and extant collaterals in the cohort strains examined (Supplemental Figs. II and III). The above findings indicate that collaterals undergo selective rarefaction at an early age in $\mathrm{AD}$.

\section{Rarefaction does not require aggregation of $A \beta$ on collaterals}

Vascular deposition of $\mathrm{A} \beta$ (CAA) on pial/leptomeningeal arteries, arterioles, intracortical PAs, and capillaries is accompanied by inflammation, impaired SMC reactivity, decreased barrier integrity, and apoptosis of vascular wall cells in mouse models of AD; CAA is also evident with both advanced aging and $\mathrm{AD}$ in humans and mouse models of $\mathrm{AD}$ [6-9, 49-51]. CAA in pial arterial vessels occurs early and progresses with aging in $2 \mathrm{xTg}$ mice (present by $\sim 6$ months $[46,47]$ ), shows early onset in intracortical while minimalto-absent in pial vessels in $1 \mathrm{xTg}$-AD mice $[42,46]$, and has not been evaluated in $3 x T g$ mice [46]. Pial collaterals have not been examined in these models. It is possible that the disturbed hemodynamics of low-velocity, bidirectional oscillating flow, and high circumferential wall stress caused by the opposing flow present in pial collaterals at baseline [26, 52], conditions which are well known to be pro-inflammatory in arteries [53, 54], make collaterals especially susceptible to aggregation of $A \beta$-depending on the genetic mutation(s) and accompanying course of $\mathrm{A} \beta$ pathology-in the $2 \times T g$ and $3 \times T g$ but not $1 \times$ Tg models, and lead to the collateral rarefaction seen in the former but not $1 \times \mathrm{Tg}$ mice. Our findings do not support this hypothesis. Widespread aggregate CAA (6E10 immunostaining), with its characteristic patchy appearance $[49-51,55,56]$, was present throughout the large-caliber branches of the pial artery trees in 8 - and 18-month-old 2xTg mice as reported previously [46, 47, 57], and extended distally with less, rather than more, intense deposition on the collaterals (Fig. 3). In contrast, no aggregates of $\mathrm{A} \beta$ were detected on pial arteries, arterioles, and collaterals in the $3 \times \mathrm{Tg}$ and $1 \times \mathrm{Tg}$ mice at 8 months of age and were only diffuse and intermittently present at 18 months of age (Fig. 3). Little or no deposition was seen on venules/ veins, as reported previously $[46,51]$, and no vascular $A \beta$ was detected in WT mice. Similar results were obtained with thioflavin-S staining and resorufin. Thus, collaterals do not experience selective early deposition, compared to pial arteries or arterioles, in the $3 \times \mathrm{Tg}$ or $1 \times \mathrm{Tg}$ mice or greater deposition in the $2 \mathrm{xTg}$ - a model of AD with extensive early CAA that progresses with age $[46,47,57]$. Likewise, rarefaction in the $3 \times T$ Tg and $2 \times T g$ strains (Fig. 1) at 8 months age does not follow the pattern of deposition on pial arteries and collaterals, i.e., present in $2 \times \mathrm{Tg}$ but not $3 \mathrm{xTg}$ mice.

\section{AD-induced collateral rarefaction coincides with the presence of parenchymal total APP/ $A \beta, C D 11 b^{+}$cells, and H0-1 expression, but does not progress as these parameters increase with aging}

We next examined whether $\mathrm{A} \beta, \mathrm{CD} 11 \mathrm{~b}^{+}$cell density (a marker for infiltrating monocytes), and activated microglia $[5,9,58,59]$ and expression of the anti-oxidant protein heme oxygenase-1 (HO-1) [60], which are associated with neural and vascular inflammation in $\mathrm{AD}$, are greater in parenchyma underlying the collaterals than in the adjacent cortex. We reasoned this could arise because the collateral/watershed zone between the crowns of the pial artery trees, which includes the underlying cortex whose perfusion is partially supplied by the PAs that branch from the collaterals, is at risk for lower oxygen levels and mitochondrial stress due to its downstream position between the trees (i.e., furthest from the "aorta") [61]. And that this might lead to greater parenchymal accumulation of $\mathrm{A} \beta$ and $C D 11 b^{+}$cells [62-64], resulting in rarefaction of collaterals by virtue of their proximity to a more pro-inflammatory environment. Our findings do not support this hypothesis. Cortex underlying the rostral, middle, and caudal collateral zone ("COL zone") between the MCA and ACA trees, and adjacent cortex underlying the DMAs of the ACA tree ("DMA zone"), was examined in $3 \times T$ Tg and WT mice (Fig. 4). Total APP/A $\beta$ did not differ for COL versus DMA zones in either strain. Controls for $6 \mathrm{E} 10$ immunostaining consisted of the positive gradient evident from caudal to rostral cortex in 18-month-old AD mice, reported previously at other ages [40], as well as that $\mathrm{A} \beta$ in $\mathrm{AD}$ mice increased between 8 and 18 months of age and became detectable in aged WT mice (Fig. 4) as reported by others $[6,8,37,40]$. Also in agreement with previous studies $[49,65,66]$, microvascular density (primarily capillaries), indicated by the endothelial cell (EC) marker Glut1, was lower in 18 versus 8-month-old WT mice, and this age-associated decline was greater in AD mice (Fig. 4). Microvascular density did not differ between collateral and DMA zones for WT and AD mice at 8 months of age (except for the caudal collateral zone of AD mice). Findings similar 

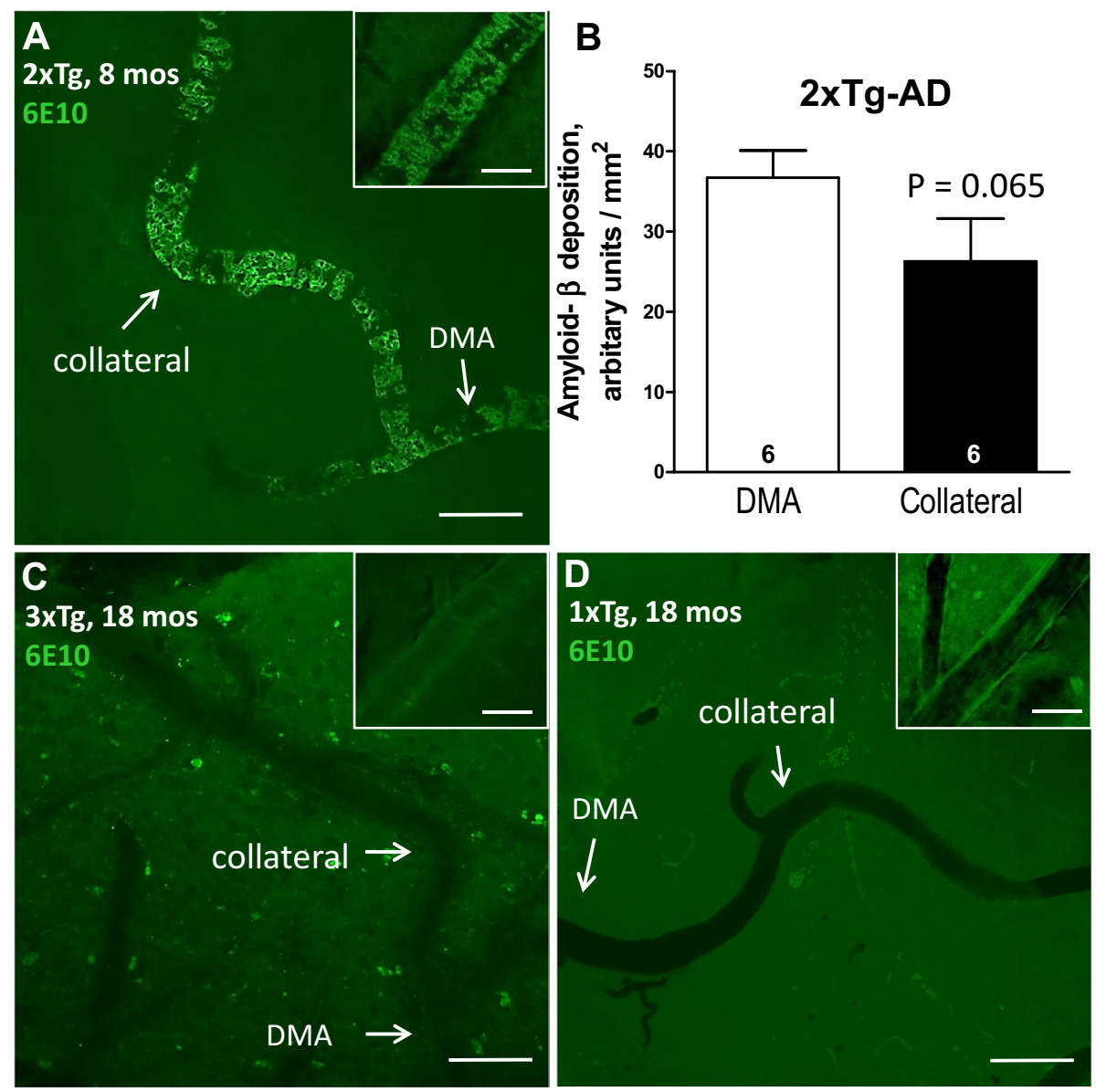

Fig. 3 Rarefaction does not require deposition of $\mathrm{A} \beta$ on collaterals. Images and data analysis were obtained from whole-mounts of the dorsal surface of the cortex. Rarefaction in 3xTg and 2xTg mice (Fig. 1) does not correlate with deposition of beta-amyloid on collaterals or upstream arterioles and arteries. $2 \times \mathrm{Tg}$ mice have strong deposition on collaterals and throughout the pial artery trees at 8 months of age $(\mathbf{a}, \mathbf{b})$, the latter which increases directly with diameter. Insets in upper right corners of $\mathbf{a}, \mathbf{c}, \mathbf{d}$ show a proximal (2nd order) arteriole at $\times 50$ magnification. By comparison, deposition in $3 \times \mathrm{Tg}(\mathbf{c})$ and

to the above for $\mathrm{A} \beta$ were obtained for $\mathrm{CD} 11 \mathrm{~b}^{+}$cell density (Fig. 5) and expression of HO-1 (Supplemental Fig. IV). $\mathrm{CD}_{11} \mathrm{~b}^{+}$cells and $\mathrm{HO}-1$, which were low or undetectable in WT mice, were present at comparable levels in the collateral and DMA zones of $3 \mathrm{x}-\mathrm{Tg}$ mice at 8 months of age and increased further by 18 months of age.

Increased levels of total $\mathrm{APP} / \mathrm{A} \beta, \mathrm{CD} 11 \mathrm{~b}^{+}$cells and $\mathrm{HO}-1$ present at 18 months of age were not accompanied by additional rarefaction (Fig. 1), even though additional rarefaction occurs in 31-month-old B6 mice (i.e., 22\% and 30\% decrease in number and diameter) [29]. This suggests that AD-induced rarefaction reaches a maximum by 8 months of age. However, mice older than 18 months of age would have to be studied to confirm this. The absence of effect of $\mathrm{AD}$ on microvascular density in cortex at 8 months of age
$1 \times \operatorname{~Tg~(d)~mice,~which~was~absent~at~} 8$ months of age in both strains, was diffused at 18 months of age in $3 \times \mathrm{Tg}$ and $1 \times \mathrm{xTg}$ mice $(\mathbf{c}, \mathbf{d})$. Focal plane was set on pial vessels and thus did not image parenchymal A $\beta$ (although both are co-imaged in c). Venules and veins had little or no deposition in the three strains at either age. Images are representative of, (for 8 and 18 months of age, respectively): $n=6,5$ for the number of $2 x \operatorname{Tg}, 3,4$ for $3 x T g$, and 3, 3 for $1 \times 19$ mice analyzed. Magnification bars, $50 \mu \mathrm{m}$

(Fig. 4), along with absence of effect on number or diameter of DMAs and PAs, further underscores that AD causes selective rarefaction of collaterals at an early age.

\section{AD-induced rarefaction is associated with increased markers of inflammation, oxidative stress, and aging of collateral wall cells}

Accumulation of intra- and extracellular $A \beta$, which occur with advanced aging and are accelerated in $\mathrm{AD}$, promote oxidative stress and inflammation in the parenchyma and cerebral vasculature [2-9, 58-63]. It is possible that these conditions combine with the above-mentioned unique local hemodynamic environment that collateral wall cells reside in: The low/disturbed shear stress, high wall stress, and 

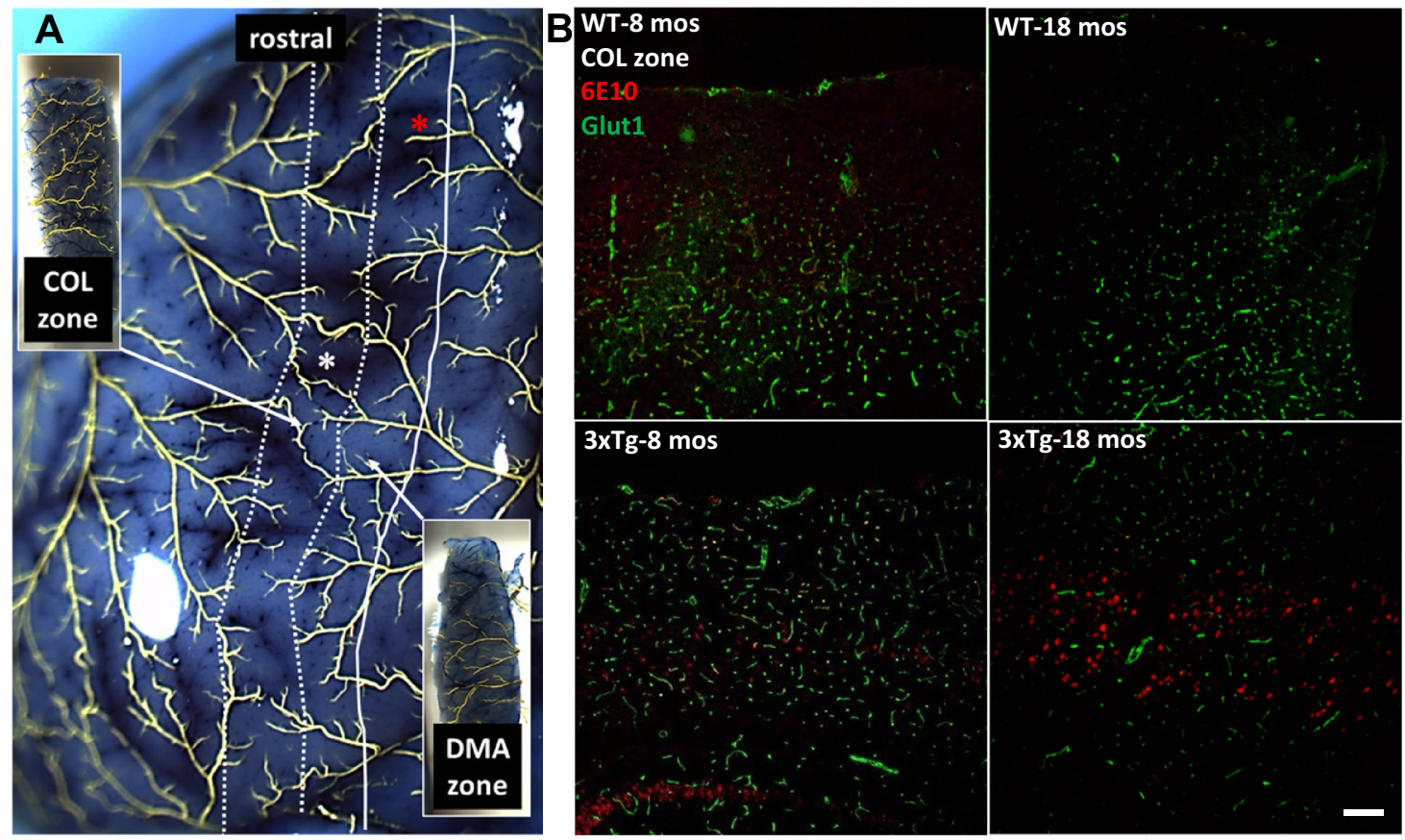

C Total APP/A $\beta$ and microvascular density in neocortex underlying collateral $(\mathrm{COL})$ zone and distal-most arterial (DMA) zone in wildtype (WT) and 3xTg-AD mice

\begin{tabular}{|c|c|c|c|c|c|c|c|c|c|}
\hline & & \multicolumn{4}{|c|}{8 months-age } & \multicolumn{4}{|c|}{18 months-age } \\
\hline & & \multicolumn{2}{|c|}{ WT } & \multicolumn{2}{|c|}{$3 x T g-A D$} & \multicolumn{2}{|c|}{ WT } & \multicolumn{2}{|c|}{$3 x T g-A D$} \\
\hline & & COL zone & DMA zone & $\mathrm{COL}$ zone & DMA zone & COL zone & DMA zone & COL zone & DMA zone \\
\hline \multirow{3}{*}{$6 \mathrm{E} 10$} & $\mathrm{R}$ & - & - & ++ & + & + & + & +++++ & ++++ \\
\hline & $M$ & - & - & + & ++ & + & + & +++ & ++++ \\
\hline & $\mathrm{C}$ & - & - & + & + & + & ++ & ++ & ++ \\
\hline \multirow{3}{*}{ Glut1 } & $\mathrm{R}$ & +++++ & +++++ & +++++ & +++++ & ++ & ++ & + & + \\
\hline & $M$ & +++++ & +++++ & +++++ & +++++ & ++ & ++ & + & + \\
\hline & C & +++++ & +++++ & ++ & +++++ & ++ & ++ & + & + \\
\hline
\end{tabular}

Fig. 4 Collateral rarefaction coincides with the presence of intracerebral total APP/A $\beta$. a Pial vasculature maximally dilated, perfused with Evans blue in PBS, and filled with Microfil ${ }^{\mathrm{R}}$. White lines delimit the collateral (COL) zone between the MCA (on the left) and ACA trees containing collaterals (white star denotes one) and the distalmost arteriole (DMA) zone of the outer ACA tree containing DMAs (red star denotes one). Insets, examples of tissue blocks of rostral (R), middle $(\mathrm{M})$, and caudal $(\mathrm{C})$ zones that were isolated for slide section histology shown in (b), Fig. 5 and Supplemental Fig. IV. b Representative sections $(10 \mu \mathrm{m})$ of middle COL and DMA zones of 8 - and 18-month-old wildtype (WT) and 3xTg-AD mice (pial surface is ori-

reduced $\mathrm{PO}_{2}$ (that is likely close to parenchymal $\mathrm{PO}_{2}$ that is $\sim 14 \mathrm{mmHg}$ at rest [67]) experienced by collaterals favor vascular inflammation and endothelial dysfunction when present elsewhere in the circulation $[53,54]$. This environment may underlie the increased cell proliferation/turnover of collateral ECs and length/tortuosity of collaterals compared to ented dorsal). $\mathbf{c}$ Total APP/A $\beta$ score (6E10 immuno-fluorescence) did not differ for cortex underlying the COL zone versus DMA zone in WT or AD mice ( $n \geq 6$ for 8 - and 18-month-old WT and 3xTg mice, respectively) and displayed a positive gradient from caudal to rostral cortex in $3 \times \mathrm{Tg}$. Total APP/A $\beta$ score burden in AD mice increased between 8 and 18 months of age and also became detectable in 18-month-old WT mice. Score for microvascular density (anti-Glut1, primarily capillaries) was lower in 18 versus 8-month-old WT mice and the decline was greater in $\mathrm{AD}$ mice. +- , variably present at a low level $(+++++$ being a high level) or absent. Magnification bars, $100 \mu \mathrm{m}$. Images scored blindly by two independent observers

DMAs - the latter a hallmark of collaterals-that increase with aging in B6 mice and coincide with collateral rarefaction $[29,31,32]$. The inflammation and oxidative stress caused by the AD pathology present in the $3 \times \mathrm{Tg}$ and $2 \times \mathrm{Tg}$ mice could increase the already-accelerated proliferation and aging of collateral wall cells present in healthy mice, 

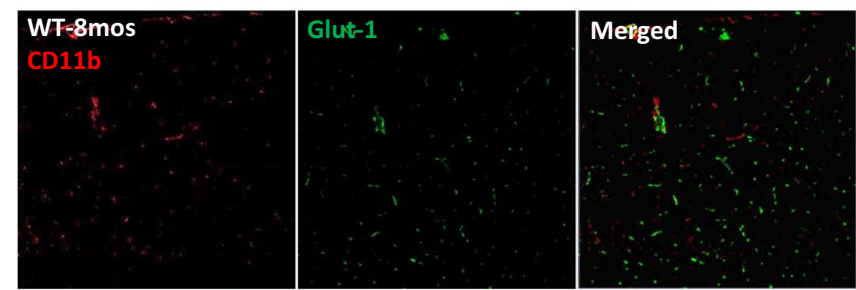

3xTg-8mos

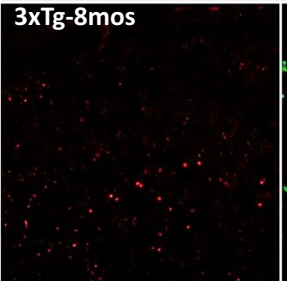

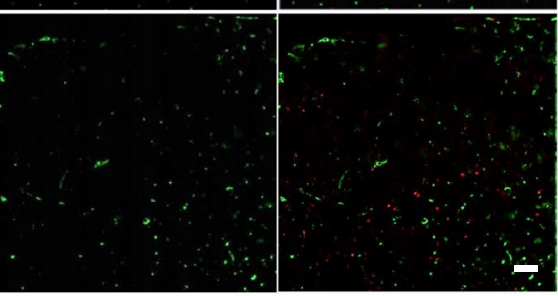

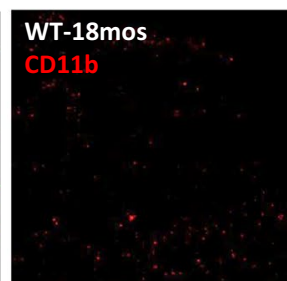

$3 \times \operatorname{Tg}-18 \mathrm{mos}$
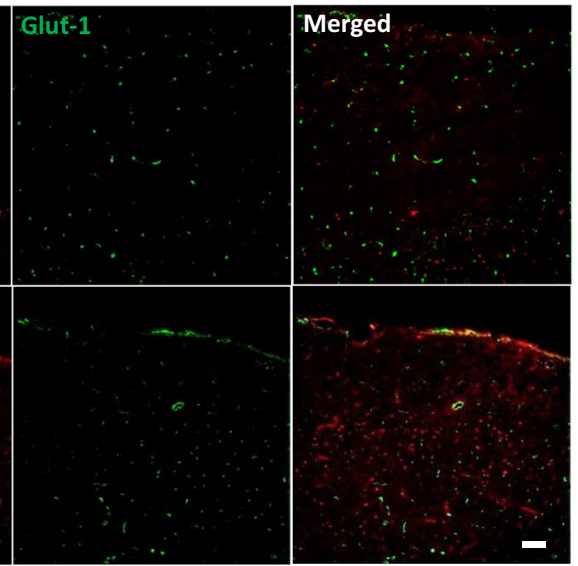

CD11b+ cell recruitment in WT and 3xTg-AD mice

\begin{tabular}{ccccccccc}
\hline \multicolumn{3}{c}{8 months-age } & \multicolumn{3}{c}{18 months-age } \\
\hline \multicolumn{3}{c}{ WT } & \multicolumn{2}{c}{$3 x T$ Th-AD } & \multicolumn{2}{c}{ WT } & \multicolumn{2}{c}{$3 x T g-A D$} \\
\hline COL & DMA & COL & DMA & COL & DMA & COL & DMA \\
zone & zone & zone & zone & zone & zone & zone & zone \\
\hline+- & +- & ++ & +++ & & +- & + & +++++ & ++++ \\
\hline
\end{tabular}

Fig. 5 Collateral rarefaction coincides with presence of intracerebral

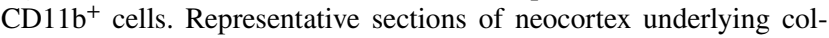
lateral (COL) zone of WT and 3xTg-AD mice (pial surface oriented dorsal). Magnification bars, $50 \mu \mathrm{m}$. Table, CD11 ${ }^{+}$score in AD mice increased between 8 and 18 months of age. DMA, distal-most arteriole; $n \geq 6$ for 8 -and 18 -month-old WT and $3 \times$ Tg mice, respectively. Images scored blindly by two independent observers

(since $3 \times \mathrm{Tg}$ mice are on a mixed $\mathrm{B} 6-129 \mathrm{~Sv}$ background) with B6.CX $\mathrm{CR}_{3} 1^{-1-}$ mice and also with B6.eNOS transgenic mice (the latter have a twofold increase in NO production [32]). Since various treatments are available that maintain or increase endothelial NO bio-availability, B6.2xTg; B6.eNOS transgenic mice were examined at 18 months age ( 56 human-year equivalents [44]) to better simulate the age when familial $\mathrm{AD}$ becomes apparent in humans. Loss of collateral number was prevented in $2 \mathrm{xTg} ; \mathrm{CX}_{3} \mathrm{CR} 1^{-1-}$ mice, and loss of both number and diameter were prevented in 2xTg; eNOS ${ }^{\mathrm{Tg}}$ mice (Fig. 8). These findings demonstrate that collateral rarefaction in young-adult AD mice involves fractalkine signaling and suggest this leads to inflammationinduced decline in eNOS/NO.

\section{Discussion}

This study yielded several important findings. Collateral rarefaction occurred by similar amounts in $2 \times \mathrm{Tg}$ and $3 \mathrm{xTg}$ mice when examined at 8 months of age ( 28 human-year equivalents [44]). No significant rarefaction was observed at 1 month of age, nor had the rarefaction at 8 months progressed significantly further at 18 months in the cohorts examined. Thus, rarefaction of collaterals in AD occurred well before that seen with natural aging, where declines 

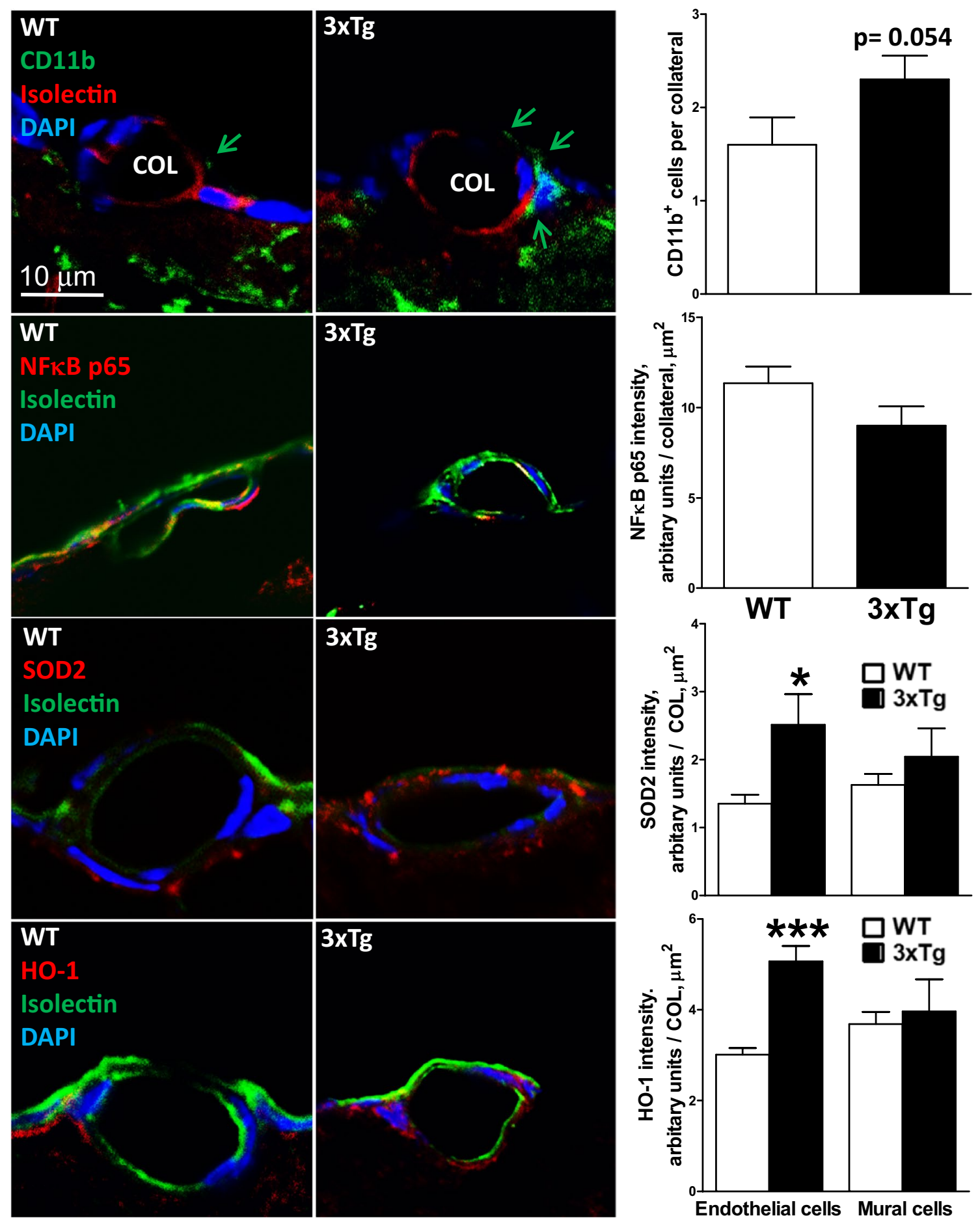

Fig. 6 AD-induced collateral rarefaction is associated with increased markers of inflammation and oxidative stress. Collaterals (COL) were identified by lumen filled with Microfil and roadmap of tissue blocked for histology per Fig. 4a. Isolectin identifies endothelial cells, DAPI identifies nuclei. 8-month-old WT and 3xTg mice. Increased $\mathrm{CD}_{11} \mathrm{~b}^{+}$perivascular cells (arrows), a marker of inflammation, and increased expression of the anti-oxidant proteins SOD2 and heme oxygenase-1 (HO-1), markers for the presence of increased oxidative cell stress. $n=5$ mice for each bar. $* * * * * * p<0.05,0.01,0.001$ versus WT. Magnification bar (first panel) same for all panels. Images scored blindly by two independent observers 

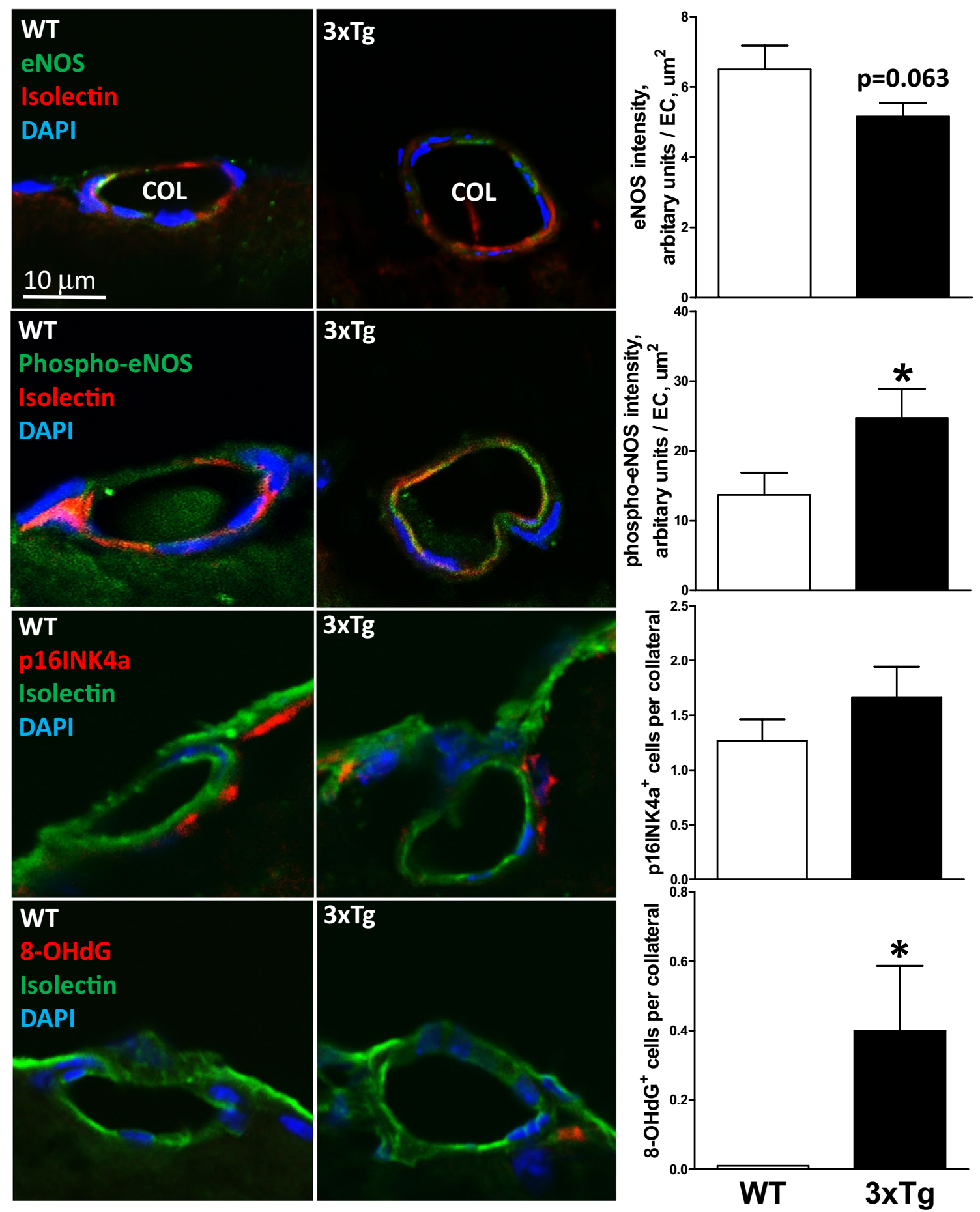

Fig. 7 AD-induced rarefaction is associated with changes in eNOS and increased markers of aging of collateral wall cells. Collaterals (COL) were identified by lumen filled with Microfil and roadmap of tissue blocked for histology per Fig. 4a. Isolectin identifies endothe- lial cells, DAPI identifies nuclei. 8-month-old WT and 3xTg mice. Increased 8-OHdG is a marker for cellular aging. $n=5$ mice for each bar. $* p<0.05$ versus WT. Magnification bar (first panel) same for all panels. Images scored blindly by two independent observers in collateral diameter and number became evident at 16 and 24 months of age ( 52 and 72 hye), respectively [29, $32]$. Rarefaction was accompanied by an increase in collateral tortuosity (31\%), which reflects an increase in EC proliferation [29, 32], and an increase in relative resistance of the collateral network (2.9-fold) and infarct volume after pMCAO (91\%). Similar changes also occurred with aging $[36,40]$. No significant rarefaction was seen in 8-month-old 

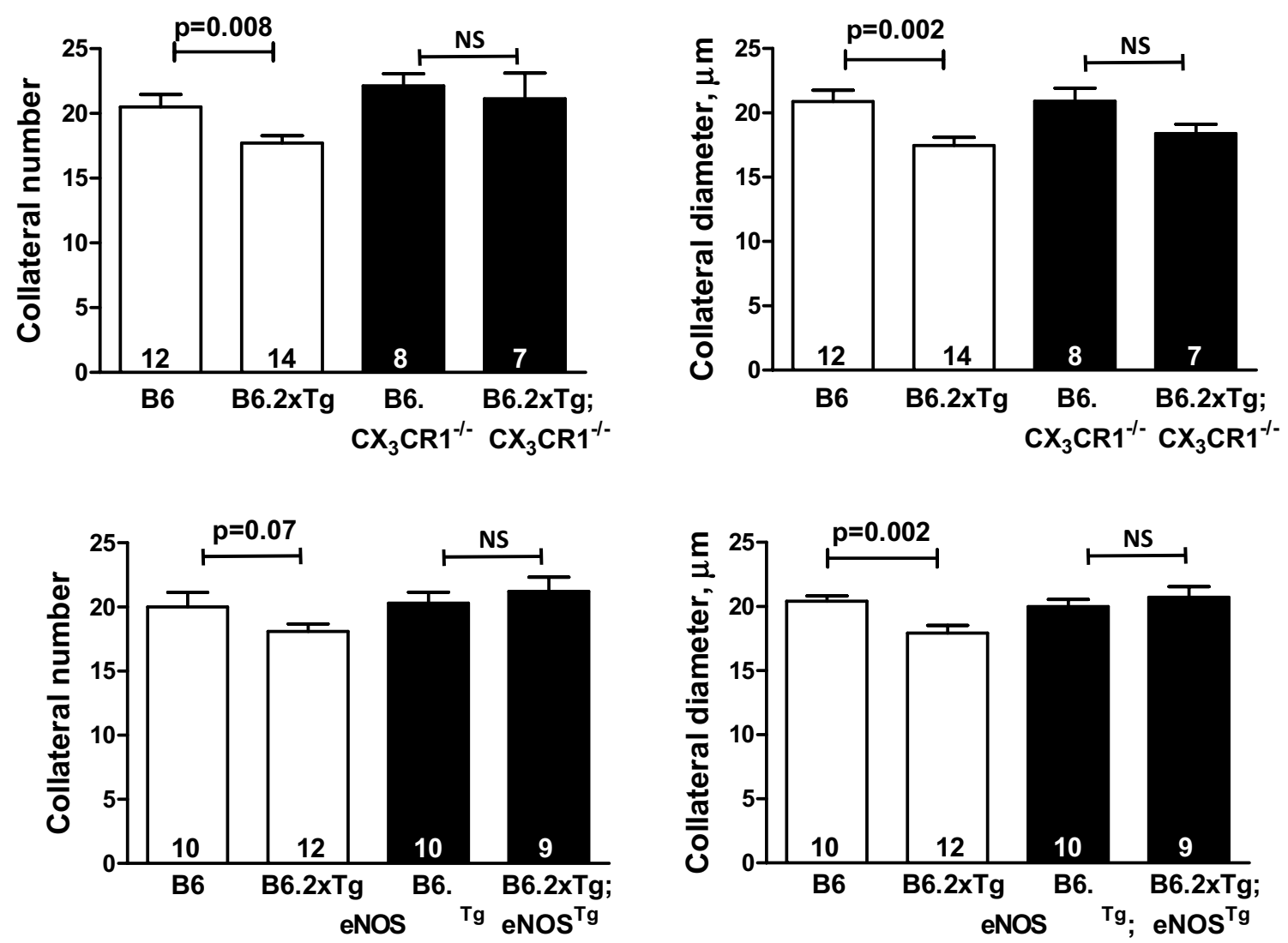

Fig. 8 AD-induced rarefaction is lessened in $\mathrm{AD}$ mice deficient in $\mathrm{CX}_{3} \mathrm{CR} 1$ and prevented by increased expression of eNOS. $\mathrm{CX}_{3} \mathrm{CR}^{-1-}$, receptor knockout mice. $\mathrm{eNOS}^{\mathrm{Tg}}$, endothelial nitric oxide synthase transgenic mice. These strains were crossed with

$1 \times T g$ mice, and only a small decrease in collateral number was present at 18 months of age. This difference in the models may reflect different mechanisms of AD pathology induced by the APPSwDI transgene present in the $1 \mathrm{xTg}$ model, which leads to $A \beta$ aggregation on intracerebral capillaries and PAs $[42,46]$. Rarefaction occurred irrespective of $\mathrm{A} \beta$ aggregation on collaterals or pial arteries, i.e., extensive deposits were present at 8 months of age in the $2 \times \mathrm{Tg}$ but absent in the $3 \times \mathrm{Tg}$ (and $1 \mathrm{xTg}$ ) mice. However, rarefaction was accompanied by elevated levels in collateral wall cells of proteins associated with increased oxidative stress, inflammation, and aging. These conditions are known to impair eNOS-derived NO [6, 29, 31, 32, 36, 37, 53, 54, 70], which is an important collateral "maintenance" factor that protects against age-associated rarefaction [29-32]. These same conditions also accompany collateral rarefaction that occurs with aging or vascular risk factors such as hypertension and metabolic syndrome [29-32]. Consistent with the above findings, rarefaction was lessened in $2 \times T g$ mice deficient in $\mathrm{CX}_{3} \mathrm{CR} 1$ and prevented by increased expression of eNOS even when examined at 18 months of age. Interestingly, increased eNOS achieved by chronic exercise training

B6.2xTg-AD mice. White bars (data from Fig. 1 to aid interpretation) and black bars indicate separate cohorts of mice. Top panels, 8 months old; bottom panels, 18 months old. NS non-significant

also prevented rarefaction and the increase in infarct volume after pMCAO that occur with advanced aging [32].

Although there is no published work on collaterals for comparison to our findings, Dorr and co-workers [49] examined PAs in TgCRND8 AD mice at 3, 6, and 12 months of age and found no significant change in length or diameter in AD or WT mice (number was not reported). A small increase in tortuosity and reduced vasodilation to $\mathrm{CO}_{2}$ was seen in 12-month-old AD mice. Increased pial vessel tortuosity, decreased intracerebral vessel density, degeneration of SMCs, and decreased blood-brain barrier integrity have been reported in humans with $\mathrm{AD}[2-7,37,49,50$, 56, 64-66].

Collateral rarefaction is likely an important contributor to the greater infarct volumes that we observed in $\mathrm{AD}$ mice, since collateral conductance and lesion size following pMCAO are primarily dependent on collateral number and diameter [23, 24]. Previous studies have reported that larger lesions and worse outcomes occur following acute ischemic stroke; however, the responsible mechanisms were unclear, thus prompting this study. In humans with $\mathrm{AD}$, combined presence of $A p o E-\varepsilon 4$ allele and CAA on autopsy increased 
the odds of having cortical infarction 3.2-fold [11]. Since atherosclerosis or small vessel disease did not account for the association, the authors concluded that "the mechanism underlying the association remains enigmatic." Other studies have found that $\mathrm{AD}$ increases the risk of ischemic stroke [14], although this was not confirmed elsewhere [12, 13]. In 3-4-month-old APP695Swe transgenic (Tg2576) mice, which had elevated $A \beta$ but not perivascular $A \beta$ deposits or neuritic plaque, blood flow in the penumbra following pMCAO was reduced twofold and infarct volume measured $24 \mathrm{~h}$ later was increased $32 \%$ [15]. The authors speculated that the findings might result from impaired collateral blood flow. Milner et al. [16] reported that young Tg2576 mice had increased infarctions after transient MCAO, and that 15-month-old Tg2576 with established CAA and neuritic plaques also had larger infarct volume and greater deficit in blood flow immediately after occlusion. The authors suggested that the latter results "likely relate to the inability of nearby CAA-laden cerebral arterioles to provide collateral blood flow through autoregulatory vasodilation." Infarct volume after pMCAO was 36\% larger in 9-month-old APP/ PS1dE9 AD mice which had extensive $A \beta$ deposits and microgliosis [17]. Similarly, in 8- and 20-month-old APP751 transgenic mice which have elevated $A \beta$ but no significant CAA or neuritic plaque, infarct volumes were $34 \%$ and $41 \%$ larger than controls [18]. Iadecola and co-workers [19] reported that 3-4-month-old $\mathrm{APP}_{695}$ Swe mice (FVB/ $n$ background) with high levels of $A \beta$ had a $42 \%$ greater decrease in blood flow in the outer MCA tree and 32\% larger infarct volume $24 \mathrm{~h}$ after pMCAO than WT controls. Other investigators found that 18 -month-old mice transgenic for mutant $A P P$, but not for $P S E N-1$, sustained larger infarct volumes after photothrombotic occlusion [20]. A lack of effect on infarct volume in PSEN-1 transgenic mice was also reported by others $[18,71,72]$. Our finding that a similar amount of collateral rarefaction occurred at 8 months of age in models of $\mathrm{AD}$ with (2xTg) and without (3xTg) CAA is congruent with the above studies and suggests that rarefaction of pial collaterals occurs early in the course of the disease in association with diffuse parenchymal amyloidosis, predisposing to increased infarctions.

Microvascular density within the parenchyma, representing primarily capillaries, was reduced in 8- and 18-monthold $3 \times \mathrm{Tg}$ mice. This could also contribute to the increased infarction that we observed after MCAO. However, based on previous studies that used genetic methods to alter collaterogenesis and thus increase or decrease collateral number and diameter without altering non-collateral vessels [24], the reductions in collateral number and diameter that occurred in the 8-month-old 3xTg mice would, alone, increase infarct volume by $\sim 100 \%$. This is close to-and not less than-the $91 \%$ increase that we observed, indicating that the increased infarct volume in the AD mice can be primarily attributed to collateral rarefaction. However, lower capillary density at baseline and/or inhibition of ischemic angiogenesis in the peri-infarct region could contribute to poorer functional outcomes in AD after acute ischemic stroke. Decreased capillary density has been reported in humans with $\mathrm{AD}[65,66]$, in double transgenic $\mathrm{AD}$ mice $[49,73]$, and in ArcAbeta $\mathrm{AD}$ mice with significant CAA [74]. APP A $\beta$ binds VEGF and Flk1 (VEGFR2) [75], and inhibits angiogenesis in vitro and in vivo [76, 77]. At 18 months of age, microvascular density was reduced in WT mice (Fig. 4), as is known to occur with advanced aging $[49,65,66]$. Reduced capillary density in $\mathrm{AD}$ and aging is congruent with loss of synapses, neurons, and brain mass that accompany both conditions.

What might underlie the selective rarefaction of collaterals seen early in the progression of $\mathrm{AD}$ and its prevention by increased expression of eNOS? Collateral rarefaction that occurs with aging and other vascular risk factors [29-31], which are accompanied by oxidative stress and endothelial/eNOS dysfunction, is inhibited-at least in the case of aging - by daily aerobic exercise, which increases eNOS expression [40]. Furthermore, robust eNOS activity is required for maintenance of collateral number during adulthood [30, 31]. Thus, the finding that $A \beta$, itself, causes oxidative stress, inflammation, and endothelial/eNOS dysfunction $[4-7,9,15,16,37]$, provides one mechanism that may underlie AD-induced collateral rarefaction. Recent findings provide additional clues. Genetic deficiency of eNOS, in both in vitro studies of human brain microvascular ECs and in vivo studies in mice, causes increased endothelial expression of APP and $\beta$-secretase-1 (BACE-1), appearance of vascular and parenchymal $A \beta$, and cognitive deficits that are prevented by administration of L-arginine or a PDE5 inhibitor [70]. The latter also improves cognitive function in APP-PS1 and Tg2576 AD mice without affecting brain amyloid burden, suggesting a vascular contribution $\mathrm{p}$ [70]. In cerebral vessels from $\mathrm{Tg} 2576 \mathrm{AD}$ mice, increased expression of $\mathrm{A} \beta$ is accompanied by increased NADPH oxidase and superoxide anion and uncoupled eNOS [70, 78]. Moreover, physiologic expression of APP in brain ECs is required to maintain normal eNOS expression, leading to the suggestion that disturbed metabolism of APP in mutant APP models of AD may lead to impaired expression of eNOS and vascular dysfunction [79]. Furthermore, senescence of human brain ECs was accompanied by increased levels of BACE- 1 and $\mathrm{A} \beta_{1-40}$, and the latter was reversed by treatment with a BACE-1 inhibitor [80]. And absence of eNOS increased $A \beta$ pathology in Tg-5xFAD mice [81]. Deficient VEGF signaling may also contribute to collateral rarefaction in AD. VEGF contributes to collateral formation during development and stabilization and maturation during growth to adulthood [25, 27]. A $\beta$ binds VEGF and Flk1 [75] and inhibits Flk1's downstream signaling pathway that includes eNOS, which is required for EC survival $[75,76]$, 
and accelerates EC senescence [77]. Inhibition of Flk1 and eNOS signaling and increased EC senescence are associated with increased production of reactive oxygen species and apoptosis of ECs [82-84].

Rarefaction was lessened in $2 \mathrm{xTg}$ mice deficient in $\mathrm{CX}_{3} \mathrm{CR} 1$, the receptor for fractalkine/ $\mathrm{CX}_{3} \mathrm{CL} 1 . \mathrm{CX}_{3} \mathrm{CR} 1$ is present on microglia, patrolling monocytes, NK cells, and cytotoxic $\mathrm{T}$ cells, and its signaling has been implicated in $\mathrm{AD}[2,5,7,9,58,59,68,69,78]$. Expression of fractalkine is induced primarily in neurons but also astrocytes, ECs, and SMCs activated by intraneuronal and extracellular $A \beta$ and other inflammatory factors. Binding of $\mathrm{A} \beta$ to microglial cells induces neuroinflammation and micro- and astrogliosis involving soluble fractalkine-mediated recruitment of activated $\mathrm{CD} 11 \mathrm{~b}^{+}$microglia and peripheral immune cells (the latter's $\mathrm{CX}_{3} \mathrm{CR} 1$ ligate membrane-bound fractalkine on activated ECs and promote transmigration) that release IL6/1 $\beta$, TNF $\alpha$, free radicals, and other cyto/chemokines $[2,5,7,9,58,59,68,69,78]$. Of note, fractalkine augmented production of reactive oxygen species in ECs and SMCs, resulting in impaired eNOS-NO that was reversed by anti-oxidant treatment [68]. Furthermore, deficiency in $\mathrm{CX}_{3} \mathrm{CR} 1$ increased microglial activation and $\mathrm{A} \beta$ clearance in $2 \times T g$ mice, lessened neuronal loss in 3xTg mice [69], and reduced $\mathrm{A} \beta$ levels in two mouse models of $\mathrm{AD}$ in an alleledose dependent manner [85]. The above findings support a role for fractalkine in $\mathrm{AD}$ pathology and suggest that the decrease in collateral rarefaction that we observed in $2 \times \mathrm{Tg}$; $\mathrm{CX}_{3} \mathrm{CR}^{-/-}$mice could result from reduced $\mathrm{A} \beta$ and/or tempered inflammatory signaling driven by intracerebral and/ or vascular $\mathrm{A} \beta$. However, depending on context, fractalkine may also exert a protective role [5]. For example, fractalkine is reduced in hippocampus and cortex of 9- and 17-monthold Tg2576 mice [86] and levels of both ligand and receptor decrease with aging in association with a decline in the ability of microglia to mount a normal response to injury [87].

Like the potential involvement of eNOS and VEGF in $\mathrm{AD}$ pathology and maintenance of collaterals in the results that we obtained in $\mathrm{eNOS}^{\mathrm{Tg}}$; $\mathrm{CX}_{3} \mathrm{CR}^{-/-}$mice, interactions between fractalkine and VEGF may also be involved in the inhibition of rarefaction in the $\mathrm{CX}_{3} \mathrm{CR}^{-/-} ; 2 \mathrm{xTg}$ mice. Fractalkine increases ADAMTS-1 (a disintegrin and metalloprotease domain with TSP repeats protein-1), which binds and sequesters VEGF, and also cleaves matrix-bound thrombospondin-1-itself increased by fractalkine- to release its anti-angiogenic and apoptosis-sensitizing EC activities [88, 89]. Both ADAMTS- 1 and thrombospondin- 1 are highly expressed in ECs and SMCs. Reduction in fractalkine signaling may thus oppose collateral rarefaction induced by A $\beta$-mediated inflammation of collateral wall cells. Additional mechanisms may also contribute to AD-induced rarefaction. Impaired autoregulation of blood flow in AD [10, 49] could increase the magnitude of disturbed shear stress and the already-increased wall stress that are unique to the collateral hemodynamic environment [26, 52], leading to endothelial dysfunction, enhanced proliferative EC senescence, and collateral rarefaction. In addition, oxygen level adjacent to collateral wall cells is predictably low due to their disturbed hemodynamics, compared to other pial arterial vessels, which may favor increased production of $A \beta$ by their ECs and SMCs [61-65] that could promote rarefaction according to the following: Since flow/shear stress in collaterals at baseline ebbs back and forth with a net value of zero [26, 52], and given that collaterals are the furthest pial arterial outposts from the aorta [61], the $\mathrm{PO}_{2}$ in collateral blood is predictably lower than elsewhere in the pial arterial vasculature. And hypoxia has been found in vitro, in vivo in animal models, and ex vivo in human brain to increase $\mathrm{A} \beta$ production and decrease degradation and clearance [63].

Based on our results and the above findings of others it is possible that, early in the course of $\mathrm{AD}$, diffuse neuronally derived $\mathrm{A} \beta$ (and possibly $\mathrm{A} \beta$ released from $\mathrm{ECs}$ [70]), which is known to cause oxidative stress and release of inflammatory mediators including fractalkine from neurons, astrocytes, and activated ECs and SMCs [2, 5, 7, 9, $58,59,68,69,78]$ leads to peri-collateral recruitment of

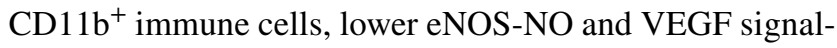
ing and other changes in collateral ECs and SMCs associated with vascular inflammation (Fig. 7). Given that eNOS-NO is well known to oppose vascular inflammation, adhesion of platelets and leukocytes, and proliferation and aging of ECs $[53,54]$, we hypothesize that the above conditions have an especially detrimental effect on collateral ECs-similar to the elevated proliferation of collateral ECs, increased tortuosity, and eventual collateral rarefaction that occurs with aging and chronic risk factor presence [29-31] which, themselves, cause increased vascular oxidative stress, inflammation, and endothelial dysfunction $[6,53,54,85]$. As well, $\mathrm{A} \beta$ has been shown to directly increase EC proliferation in vitro [97]. Collateral pruning could thus extend from chronic, low-grade, $A \beta$ inflammation-induced accelerated EC proliferative senescence in association with decreased eNOS, VEGFA-Flk1 signaling [75], and changes in other downstream effector proteins, resulting in EC destabilization, pericyte loss, increased perivascular leukocytes, EC and SMC apoptosis, decline in vessel diameter, and eventual vessel end-closure, and loss of the collateral anastomosis. Interestingly, if basement membrane sleeves/strings persist after collateral pruning, as has been reported with other types of vessel pruning [65, 66], it might be possible to induce collaterals that have been lost to re-grow through such extant scaffolds.

Like all scientific studies, our results are conditional and subject to limitations. The mice studied herein are highly aggressive models of human familial $\mathrm{AD}$ and do not model the late-onset sporadic form of the disease that is much 
more common in humans. A second limitation is that our studies are in mice, not humans. A third limitation is that the interpretation of the data shown in Fig. 8 for the $2 x T g$; $\mathrm{CX}_{3} \mathrm{CR}^{-/-}$and $2 \mathrm{xTg}$; eNOS transgenic mice would be more compelling, regarding mechanism, if these genetic crosses had also been evaluated for intracerebral $\mathrm{A} \beta, \mathrm{CD} 11 \mathrm{~b}^{+}$cells and the measures shown in Figs. 6 and 7 for inflammatory, oxidative stress, and aging markers. Not only is this an important control measurement, but how $\mathrm{A} \beta$ dose relates to collateral dysfunction might provide insight into how regional $A \beta$ changes contribute to worsened blood flow and ischemia outcomes. A fourth limitation is that the rescue outcomes observed in the $\mathrm{B} 6.2 \mathrm{xTg}$; $\mathrm{B} 6 . \mathrm{CX}_{3} \mathrm{CR} 1^{-/-}$and B6.2xTg; B6.eNOS ${ }^{\mathrm{Tg}}$ mice were not tested for confirmation in the $3 \times \mathrm{TT}$ model. This was because the latter are on a mixed B6-129Sv background, thus transferring the knockout and transgenic alleles onto a near-pure B6-129Sv background would require 10 generations of backcrossing. A fifth limitation is that comparison of parenchymal $A \beta$ between the three AD mouse models at 8 and 18 months of age would have aided interpretation (i.e., Do $1 \times$ Tg express less $A \beta$ than $2 x T g$ and $3 x T g$ mice?). Unfortunately, we are unaware of a previous publication that compared 6E10 staining in the three mouse models examined herein. However, at 8 months of age, collateral rarefaction had occurred to similar degrees in 8-month-old $2 \times \mathrm{Tg}$ and $3 \times \mathrm{Tg}$ mice, but was absent in 1xTg mice (Fig. 1). We therefore examined whether the rarefaction was associated with parenchymal $\mathrm{A} \beta$ in $3 \times \mathrm{xTg}$ mice (Fig. 4). A-beta was present at 8 months of age but was much stronger by 18 months of age, yet rarefaction was not greater at 18 months versus 8 months of age. As stated in Results and in Discussion, this indicates that rarefaction occurs early in $3 \times \mathrm{Tg}$ mice when $A \beta$ accumulation is moderate and does not become more severe when $\mathrm{A} \beta$ is much more prevalent, suggesting that the relationship is not a simple 1-to-1. An addition caveat is that other changes resulting from transgenic co-expression of mutant APP and presenilin-1, in addition to collateral rarefaction, could contribute to the increased infarct volume that we observed. These include a possible increase in neuronal sensitivity to ischemia or increase in resistance within the MCA territory to collateral-dependent perfusion after pMCAO that could arise from impaired vasodilation, leukocyte and platelet adhesion, rheological changes, and edema. However, data obtained with different targeted mutations of the gene, Rabep2, that cause graded reductions in collateral formation during development and thus fewer collaterals of smaller diameter and increased infarct volumes in the adult [24], do not support this caveat. Those data show that the magnitude of reduction in the number and diameter of collaterals that occurred in the 8-month-old 3xTg mice in the present study would, alone, increase infarct volume by $\sim 100 \%$, which is close to the $91 \%$ increase that we observed.
In conclusion, we found that two mouse models of $\mathrm{AD}$ caused selective loss of collateral number and diameter between 1 and 8 months of age and increased lesion volume following pMCAO. These findings add collateral rarefaction to the other vascular impairments that accompany and may contribute to the progression of $\mathrm{AD}[6-10,56$, $70,76-78,82-84]$. They also identify a mechanism that may contribute to the increased stroke risk, lesion size, and worse outcomes following acute ischemic stroke in $\mathrm{AD}$ patients and mouse models of AD. It will be important in future studies to examine collateral rarefaction in a next-generation mouse model(s) of sporadic AD [90, 91], and if confirmed, test for association of collateral score in acute ischemic stroke patients with and without AD. Additional studies are required to identify the cell types that express fractalkine/CX $\mathrm{CL}_{3} 1$ and its $\mathrm{CX}_{3} \mathrm{CR} 1$ receptor that are involved in the rarefaction, and to identify the pathway activated by $\mathrm{CX}_{3} \mathrm{CR} 1$, as well as other mechanisms, that lead to the impaired eNOS/NO known to occur in $\mathrm{AD}[6,36-38,70,83]$ and that when countered in our 2xTg; eNOS transgenic mice prevented rarefaction. Many inflammatory mediators released by activated microglia and peripheral immune cells impair eNOS/NO and accelerate proliferation and apoptosis of ECs and SMCs. It would also be interesting to examine whether strategies to chronically augment eNOS/NO (e.g., PDE5 inhibitor, NO donor, L-arginine, regular aerobic exercise [32, 92]), if begun early in $\mathrm{AD}$, inhibit collateral rarefaction. Previous work in mice has shown that maintenance of collaterals depends on robust expression of eNOS at baseline [30, 31 , and that aging and other vascular risk factors that cause endothelial dysfunction lead to collateral rarefaction in brain and other tissues [29-32]. The current study adds $\mathrm{AD}$ to this list of conditions and diseases that may adversely affect the cerebral collateral circulation.

Acknowledgements The authors thank Dr. Donna Wilcock (University of Kentucky) for advice on antibodies and staining methods for detection of $A \beta$, Esteban Oyarzabal (University of North Carolina) for assistance with trouble shooting several immunohistochemistry assays, Ashley Ezzell and the UNC Histology Research Core for tissue sectioning, and Dr. Paul W Stewart, Biostatistics Department, School of Public Health for statistical advice [3]. JF and HZ designed the study. JF wrote the manuscript. $\mathrm{HZ}$ performed angiography, pMCAO, statistical analysis, and animal husbandry. $\mathrm{HZ}$ and BJ performed morphometry and immunohistochemistry.

Funding This work was supported by National Institutes of Health, National Institute of Neurological Disorders and Stroke Grant No. NS083633.

\section{Compliance with ethical standards}

Conflict of interest The authors declare that they have no conflict of interest. 
Ethical approval All applicable international, national, and/or institutional guidelines for the care and use of animals were followed, including the National Institutes of Health Guide for the Care and Use of Laboratory Animals. This article does not contain any studies with human participants performed by any of the authors.

Open Access This article is distributed under the terms of the Creative Commons Attribution 4.0 International License (http://creativeco mmons.org/licenses/by/4.0/), which permits unrestricted use, distribution, and reproduction in any medium, provided you give appropriate credit to the original author(s) and the source, provide a link to the Creative Commons license, and indicate if changes were made.

\section{References}

1. Alzheimer's Association (2018) Alzheimer's disease facts and figures. Alzheimers Dement 14:367-429

2. Selkoe DJ, Hardy J (2016) The amyloid hypothesis of Alzheimer's disease at 25 years. EMBO Mol Med 8:595-608

3. Scheltens P, Blennow K, Breteler MM, de Strooper B, Frisoni GB, Salloway S, Van der Flier WM (2016) Alzheimer's disease. Lancet 388:505-517

4. De Strooper B, Karran E (2016) The cellular phase of Alzheimer's disease. Cell 164:603-615

5. Ransohoff RM (2016) How neuroinflammation contributes to neurodegeneration. Science 353:777-783

6. Iadecola $C$ (2017) The neurovascular unit coming of age: a journey through neurovascular coupling in health and disease. Neuron 96:17-42

7. Kisler K, Nelson AR, Montagne A, Zlokovic BV (2017) Cerebral blood flow regulation and neurovascular dysfunction in Alzheimer disease. Nat Rev Neurosci 18:419-434

8. Charidimou A, Boulouis G, Gurol ME, Ayata C, Bacskai BJ, Frosch MP, Viswanathan A, Greenberg SM (2017) Emerging concepts in sporadic cerebral amyloid angiopathy. Brain 140:1829-1850

9. Pimentel-Coelho PM, Rivest S (2012) The early contribution of cerebrovascular factors to the pathogenesis of Alzheimer's disease. Eur J Neurosci 35:1917-1937

10. Marshall RS (2012) Effects of altered cerebral hemodynamics on cognitive function. J Alzheimers Dis 32:633-642

11. Schneider JA, Bienias JL, Wilson RS, Berry-Kravis E, Evans DA, Bennett DA (2005) The apolipoprotein E epsilon4 allele increases the odds of chronic cerebral infarction detected at autopsy in older persons. Stroke 36:954-959

12. Cook M, Baker N, Lanes S, Bullock R, Wentworth C, Arrighi HM (2015) Incidence of stroke and seizure in Alzheimer's disease dementia. Ageing 44:695-699

13. Zhou J, Yu JT, Wang HF, Meng XF, Tan CC, Wang J, Wang C, Tan L (2015) Association between stroke and Alzheimer's disease: systematic review and meta-analysis. J Alzheimers Dis 43:479-489

14. Chi NF, Chien LN, Ku HL, Hu CJ, Chiou HY (2013) Alzheimer disease and risk of stroke: a population-based cohort study. Neurology 80:705-711

15. Zhang F, Eckman C, Younkin S, Hsiao KK, Iadecola C (1997) Increased susceptibility to ischemic brain damage in transgenic mice overexpressing the amyloid precursor protein. J Neurosci 17:7655-7661

16. Milner E, Zhou ML, Johnson AW, Vellimana AK, Greenberg JK, Holtzman DM, Han BH, Zipfel GJ (2014) Cerebral amyloid angiopathy increases susceptibility to infarction after focal cerebral ischemia in Tg2576 mice. Stroke 45:3064-3069

17. Heikkinen R, Malm T, Heikkilä J, Muona A, Tanila H, Koistinaho M, Koistinaho J (2014) Susceptibility to focal and global brain ischemia of Alzheimer mice displaying a $\beta$ deposits: effect of immunoglobulin. Aging Dis 5:76-87

18. Koistinaho M, Kettunen MI, Goldsteins G, Keinänen R, Salminen A, Ort M, Bures J, Liu D, Kauppinen RA, Higgins LS, Koistinaho J (2002) Beta-amyloid precursor protein transgenic mice that harbor diffuse A beta deposits but do not form plaques show increased ischemic vulnerability: role of inflammation. Proc Natl Acad Sci USA 99:1610-1615

19. Hsiao KK, Borchelt DR, Olson K, Johannsdottir R, Kitt C, Yunis W, Xu S, Eckman C, Younkin S, Price D, Iadecola C, Clark B, Carlson G (1995) Age-related CNS disorder and early death in transgenic FVB/N mice overexpressing Alzheimer amyloid precursor proteins. Neuron 15:1203-1218

20. Li G, Zou L, Jack CR Jr, Yang Y, Yang ES (2007) Neuroprotective effect of coenzyme Q10 on ischemic hemisphere in aged mice with mutations in the amyloid precursor protein. Neurobiol Aging 28:877-882

21. Bang OY, Goyal M, Liebeskind DS (2015) Collateral circulation in ischemic stroke: assessment tools and therapeutic strategies. Stroke 46:3302-3309

22. Ginsberg MD (2018) The cerebral collateral circulation: relevance to pathophysiology and treatment of stroke. Neuropharmacology 134:280-292

23. Zhang H, Prabhakar P, Sealock RW, Faber JE (2010) Wide genetic variation in the native pial collateral circulation is a major determinant of variation in severity of stroke. J Cereb Blood Flow Metab 30:923-934

24. Lucitti JL, Sealock R, Buckley BK, Zhang H, Xiao L, Dudley AC, Faber JE (2016) Variants of Rab GTPase-effector binding protein- 2 cause variation in the collateral circulation and severity of stroke. Stroke 47:3022-3031

25. Clayton JA, Chalothorn D, Faber JE (2008) Vascular endothelial growth factor-A specifies formation of native collaterals and regulates collateral growth in ischemia. Circ Res 103:1027-1036

26. Chalothorn D, Faber JE (2010) Formation and maturation of the native cerebral collateral circulation. J Mol Cell Cardiol 49:251-259

27. Lucitti JL, Mackey J, Morrison JC, Haigh JJ, Adams RH, Faber JE (2012) Formation of the collateral circulation is regulated by vascular endothelial growth factor-A and a disintegrin and metalloprotease family members 10 and 17 . Circ Res 111:1539-1550

28. Lucitti JL, Tarte NJ, Faber JE (2015) Chloride intracellular channel 4 is required for maturation of the cerebral collateral circulation. Am J Physiol Heart Circ Physiol 309:H1141-H1150

29. Faber JE, Zhang H, Lassance-Soares RM, Prabhakar P, Najafi AH, Burnett MS, Epstein SE (2011) Aging causes collateral rarefaction and increased severity of ischemic injury in multiple tissues. Arterioscler Thromb Vasc Biol 31:1748-1756

30. Dai X, Faber JE (2010) eNOS deficiency causes collateral vessel rarefaction and impairs activation of a cell cycle gene network during arteriogenesis. Circ Res 106:1870-1881

31. Moore SM, Zhang H, Maeda N, Doerschuk CM, Faber JE (2015) Cardiovascular risk factors cause premature rarefaction of the collateral circulation and greater ischemic tissue injury. Angiogenesis $18: 265-281$

32. Rzechorzek W, Zhang H, Buckley BK, Hua H, Pomp D, Faber JE (2017) Exercise training prevents rarefaction of pial collaterals and increased severity of stroke with aging. J Cereb Blood Flow Metab 37:3544-3555

33. Menon BK, Smith EE, Coutts SB, Welsh DG, Faber JE, Damani Z, Goyal M, Hill MD, Demchuk AM, Hee Cho K-H, Chang 
H-W, Hong J-H, Sohn SI (2013) Leptomeningeal collaterals are associated with modifiable metabolic risk factors. Ann Neurol 74:241-248

34. Malik N, Hou Q, Vagal A, Patrie J, Xin W, Michel P, Eskandari A, Jovin T, Wintermark M (2014) Demographic and clinical predictors of leptomeningeal collaterals in stroke patients. J Stroke Cerebrovasc Dis 23:2018-2022

35. Arsava EM, Vural A, Akpinar E, Gocmen R, Akcalar S, Oguz KK, Topcuoglu MA (2014) The detrimental effect of aging on leptomeningeal collaterals in ischemic stroke. J Stroke Cerebrovasc Dis 23:421-426

36. Santos CY, Snyder PJ, Wu WC, Zhang M, Echeverria A, Alber J (2017) Pathophysiologic relationship between Alzheimer's disease, cerebrovascular disease, and cardiovascular risk: a review and synthesis. Alzheimers Dement (Amst) 7:69-87

37. Iadecola C (2016) Vascular and metabolic factors in Alzheimer's disease and related dementias: introduction. Cell Mol Neurobiol 36:151-154

38. Perrotta M, Lembo G, Carnevale D (2016) Hypertension and dementia: epidemiological and experimental evidence revealing a detrimental relationship. Int J Mol Sci 17:347

39. Lyros E, Bakogiannis C, Liu Y, Fassbender K (2014) Molecular links between endothelial dysfunction and neurodegeneration in Alzheimer's disease. Curr Alzheimer Res 11:18-26

40. Oddo S, Caccamo A, Shepherd JD, Murphy MP, Golde TE, Kayed R, Metherate R, Mattson MP, Akbari Y, LaFerla FM (2003) Triple-transgenic model of Alzheimer's disease with plaques and tangles: intracellular Abeta and synaptic dysfunction. Neuron 39:409-421

41. Savonenko A, Xu GM, Melnikova T, Morton JL, Gonzales V, Wong MP, Price DL, Tang F, Markowska AL, Borchelt DR (2005) Episodic-like memory deficits in the APPswe/PS1dE9 mouse model of Alzheimer's disease: relationships to beta-amyloid deposition and neurotransmitter abnormalities. Neurobiol Dis 18:602-617

42. Davis J, Xu F, Deane R, Romanov G, Previti ML, Zeigler K, Zlokovic BV, Van Nostrand WE (2004) Early-onset and robust cerebral microvascular accumulation of amyloid beta-protein in transgenic mice expressing low levels of a vasculotropic Dutch/ Iowa mutant form of amyloid beta-protein precursor. J Biol Chem 279:20296-20306

43. Faber JE, Moore SM, Lucitti JL, Aghajanian A, Zhang H (2016) Sex differences in the cerebral collateral circulation. Transl Stroke Res 8:273-283

44. Flurkey K, Currer JM, Harrison DE (2007) Mouse models in aging research. In Fox JG et al (eds) The mouse in biomedical research, 2nd edn. Elsevier, Amsterdam, pp 637-672

45. Ryman D, Gao Y, Lamb BT (2008) Genetic loci modulating amyloid-beta levels in a mouse model of Alzheimer's disease. Neurobiol Aging 8:1190-1198

46. Jäkel L, Van Nostrand WE, Nicoll JAR, Werring DJ, Verbeek MM (2017) Animal models of cerebral amyloid angiopathy. Clin Sci (Lond) 131:2469-2488

47. Garcia-Alloza M, Robbins EM, Zhang-Nunes SX, Purcell SM, Betensky RA, Raju S, Prada C, Greenberg SM, Bacskai BJ, Frosch MP (2006) Characterization of amyloid deposition in the APPswe/PS1dE9 mouse model of Alzheimer disease. Neurobiol Dis 24:516-524

48. Brewer JB (2009) Fully-automated volumetric MRI with normative ranges: translation to clinical practice. Behav Neurol 21:21-28

49. Dorr A, Sahota B, Chinta LV, Brown ME, Lai AY, Ma K, Hawkes CA, McLaurin J, Stefanovic B (2012) Amyloid- $\beta$-dependent compromise of microvascular structure and function in a model of Alzheimer's disease. Brain 135:3039-3050
50. Nicolakakis N, Hamel E (2011) Neurovascular function in Alzheimer's disease patients and experimental models. J Cereb Blood Flow Metab 31:1354-1370

51. Domnitz SB, Robbins EM, Hoang AW, Garcia-Alloza M, Hyman BT, Rebeck GW, Greenberg SM, Bacskai BJ, Frosch MP (2005) Progression of cerebral amyloid angiopathy in transgenic mouse models of Alzheimer disease. J Neuropathol Exp Neurol 64:588-594

52. Toriumi H, Tatarishvili J, Tomita M, Tomita Y, Unekawa M, Suzuki N (2009) Dually supplied T-junctions in arteriolo-arteriolar anastomosis in mice. Key to local hemodynamic homeostasis in normal and ischemic states? Stroke 40:3378-3383

53. Chiu JJ, Chien S (2011) Effects of disturbed flow on vascular endothelium: pathophysiological basis and clinical perspectives. Physiol Rev 91:327-387

54. Zakkar M, Angelini GD, Emanueli C (2016) Regulation of vascular endothelium inflammatory signaling by shear stress. Curr Vasc Pharmacol 14:181-186

55. Dong J, Revilla-Sanchez R, Moss S, Haydon PG (2010) Multiphoton in vivo imaging of amyloid in animal models of Alzheimer's disease. Neuropharmacology 59:268-275

56. Auriel E, Greenberg SM (2012) The pathophysiology and clinical presentation of cerebral amyloid angiopathy. Curr Atheroscler Rep $14: 343-350$

57. Michaud JP, Bellavance MA, Préfontaine P, Rivest S (2013) Realtime in vivo imaging reveals the ability of monocytes to clear vascular amyloid beta. Cell Rep 5:646-653

58. Réaux-Le Goazigo A, Van Steenwinckel J, Rostène W, Mélik Parsadaniantz S (2013) Current status of chemokines in the adult CNS. Prog Neurobiol 104:67-92

59. Meyer-Luehmann M, Prinz M (2015) Myeloid cells in Alzheimer's disease: culprits, victims or innocent bystanders? Trends Neurosci 38:659-668

60. Barone E, Butterfield DA (2015) Insulin resistance in Alzheimer disease: is heme oxygenase-1 an Achille's heel? Neurobiol Dis 84:69-77

61. Momjian-Mayor I, Baron JC (2005) The pathophysiology of watershed infarction in internal carotid artery disease: review of cerebral perfusion studies. Stroke 36:567-577

62. Zabel M, Nackenoff A, Kirsch WM, Harrison FE, Perry G, Schrag M (2018) Markers of oxidative damage to lipids, nucleic acids and proteins and antioxidant enzymes activities in Alzheimer's disease brain: a meta-analysis in human pathological specimens. Free Radic Biol Med 115:351-360

63. Zhang X, Le W (2010) Pathological role of hypoxia in Alzheimer's disease. Exp Neurol 223:299-303

64. Brown WR (2010) A review of string vessels or collapsed, empty basement membrane tubes. J Alzheimers Dis 21:725-739

65. Brown WR, Thore CR (2011) Review: cerebral microvascular pathology in ageing and neurodegeneration. Neuropathol Appl Neurobiol 37:56-74

66. Sagare AP, Bell RD, Zlokovic BV (2012) Neurovascular dysfunction and faulty amyloid $\beta$-peptide clearance in Alzheimer disease. Cold Spring Harb Perspect Med 2(10):1-17. https://doi. org/10.1101/cshperspect.a011452

67. Kasischke KA, Lambert EM, Panepento B, Sun A, Gelbard HA, Burgess RW, Foster TH, Nedergaard M (2011) Two-photon NADH imaging exposes boundaries of oxygen diffusion in cortical vascular supply regions. J Cereb Blood Flow Metab 31:68-81

68. Schäfer A, Schulz C, Fraccarollo D, Tas P, Leutke M, Eigenthaler M, Seidl S, Heider P, Ertl G, Massberg S, Bauersachs J (2007) The CX3CL1 chemokine fractalkine induces vascular dysfunction by generation of superoxide anions. Arterioscler Thromb Vasc Biol 27:55-62

69. Merino JJ, Muñetón-Gómez V, Alvárez MI, Toledano-Díaz A (2016) Effects of CX3CR1 and fractalkine chemokines in amyloid 
beta clearance and p-Tau accumulation in Alzheimer's disease rodent models: is fractalkine a systemic biomarker for AD? Curr Alzheimer Res 13:403-412

70. Katusic ZS, Austin SA (2016) Neurovascular protective function of endothelial nitric oxide-recent advances. Circ J 80:1499-1503

71. Grilli M, Diodato E, Lozza G, Brusa R, Casarini M, Uberti D, Rozmahel R, Westaway D, St George-Hyslop P, Memo M, Ongini E (2000) Presenilin-1 regulates the neuronal threshold to excitotoxicity both physiologically and pathologically. Proc Natl Acad Sci USA 97:12822-12827

72. Koistinaho M, Kettunen MI, Holtzman DM, Kauppinen RA, Higgins LS, Koistinaho J (2002) Expression of human apolipoprotein E downregulates amyloid precursor protein-induced ischemic susceptibility. Stroke 33:1905-1910

73. Lee GD, Aruna JH, Barrett PM, Lei DL, Ingram DK, Mouton PR (2005) Stereological analysis of microvascular parameters in a double transgenic model of Alzheimer's disease. Brain Res Bull 65:317-322

74. Klohs J, Baltes C, Princz-Kranz F, Ratering D, Nitsch RM, Knuesel I, Rudin M (2012) Contrast-enhanced magnetic resonance microangiography reveals remodeling of the cerebral microvasculature in transgenic ArcA $\beta$ mice. J Neurosci 32:1705-1713

75. Yang SP, Bae DG, Kang HJ, Gwag BJ, Gho YS, Chae CB (2004) Co-accumulation of vascular endothelial growth factor with betaamyloid in the brain of patients with Alzheimer's disease. Neurobiol Aging 25:283-290

76. Patel NS, Mathura VS, Bachmeier C, Beaulieu-Abdelahad D, Laporte V, Weeks O, Mullan M, Paris D (2010) Alzheimer's betaamyloid peptide blocks vascular endothelial growth factor mediated signaling via direct interaction with VEGFR-2. J Neurochem 112:66-76

77. Donnini S, Solito R, Cetti E, Corti F, Giachetti A, Carra S, Beltrame M, Cotelli F, Ziche M (2010) Abeta peptides accelerate the senescence of endothelial cells in vitro and in vivo, impairing angiogenesis. FASEB J 24:2385-2395

78. Wilkinson BL, Landreth GE (2006) The microglial NADPH oxidase complex as a source of oxidative stress in Alzheimer's disease. J Neuroinflamm 3:30-41

79. d'Uscio LV, He T, Santhanam AV, Katusic ZS (2017) Endothelium-specific amyloid precursor protein deficiency causes endothelial dysfunction in cerebral arteries. J Cereb Blood Flow Metab 38:1715-1726

80. Sun R, He T, Pan Y, Katusic ZS (2018) Effects of senescence and angiotensin II on expression and processing of amyloid precursor protein in human cerebral microvascular endothelial cells. Aging 10:100-114

81. Hu ZI, Kotarba AM, Van Nostrand WE (2013) Absence of nitric oxide synthase 3 increases amyloid $\beta$-protein pathology in $\mathrm{Tg}$ 5xFAD mice. Neurosci Med 4:84-91

82. Xu J, Chen S, Ku G, Ahmed SH, Xu J, Chen H, Hsu CY (2001) Amyloid beta peptide-induced cerebral endothelial cell death involves mitochondrial dysfunction and caspase activation. $\mathrm{J}$ Cereb Blood Flow Metab 21:702-710

83. Iadecola C (2004) Neurovascular regulation in the normal brain and in Alzheimer's disease. Nat Rev Neurosci 5:347-360

84. Hayashi S, Sato N, Yamamoto A, Ikegame Y, Nakashima S, Ogihara T, Morishita R (2009) Alzheimer disease-associated peptide, amyloid beta40, inhibits vascular regeneration with induction of endothelial autophagy. Arterioscler Thromb Vasc Biol 29:1909-1915

85. Lee S, Varvel NH, Konerth ME, Xu G, Cardona AE, Ransohoff RM, Lamb BT (2010) CX3CR1 deficiency alters microglial activation and reduces beta-amyloid deposition in two Alzheimer's disease mouse models. Am J Pathol 177:2549-2562

86. Duan RS, Yang X, Chen ZG, Lu MO, Morris C, Winblad B, Zhu J (2008) Decreased fractalkine and increased IP-10 expression in aged brain of APP(swe) transgenic mice. Neurochem Res 33:1085-1089

87. Harry GJ (2013) Microglia during development and aging. Pharmacol Ther 139:313-326

88. Lee NV, Sato M, Annis DS, Loo JA, Wu L, Mosher DF, IruelaArispe ML (2006) ADAMTS1 mediates the release of antiangiogenic polypeptides from TSP1 and 2. EMBO J 25:5270-5283

89. Boscolo E, Folin M, Nico B, Grandi C, Mangieri D, Longo V, Scienza R, Zampieri P, Conconi MT, Parnigotto PP, Ribatti D (2007) Beta amyloid angiogenic activity in vitro and in vivo. Int J Mol Med 19:581-587

90. Sasaguri H, Nilsson P, Hashimoto S, Nagata K, Saito T, De Strooper B, Hardy J, Vassar R, Winblad B, Saido TC (2017) APP mouse models for Alzheimer's disease preclinical studies. EMBO J 36:2473-2487

91. Sasner M, Oblak A, Williams H, Howell G, Lamb BT, MODELAD consortium (2017). https://www.eposters.net/poster/model -ad-the-disease-modeling-project

92. Sofi F, Valecchi D, Bacci D, Abbate R, Gensini GF, Casini A, Macchi C (2011) Physical activity and risk of cognitive decline: a meta-analysis of prospective studies. J Intern Med 269:107-117 